\title{
Tradiciones críticas encontradas en torno a la literatura testimonial del Holocausto y a la literatura del testimonio ${ }^{1}$
}

\author{
Patricia Cifre Wibrow \\ Universidad de Salamanca
}

\begin{abstract}
Resumen:
En el presente ensayo se analiza el posicionamiento adoptado por parte de la crítica literaria a ambos lados del Atlántico frente al testimonio en tanto que instrumento de denuncia de injusticias perpetradas en contextos históricos traumáticos. Ello se lleva a cabo a través del análisis de los escándalos por los que se vieron rodeados los testimonios de Rigoberta Menchú (activista guatemalteca que obtuvo el Premio Nobel de la paz en 1992), Enric Marco (Presidente de la Sociedad Amical de Mauthausen y otros campos y de todas las víctimas del nazismo de España) y Binjamin Wilkomirski (famoso por una autobiografía en la que describía sus supuestas experiencias en los campos de exterminio nazis). Las reacciones suscitadas por dichos escándalos ilustran el distinto papel atribuido a la categoría de la autenticidad testimonial y autobiográfica por parte de la tradición crítica surgida en torno a la Shoah y por parte de la que se ha desarrollado a partir de la literatura del testimonio latinoamericano. Lo que se pretende mostrar aquí es que las diferencias observables en cuanto a las delimitaciones trazadas entre los géneros ficcionales y los no ficcionales se ven fuertemente determinadas por la memoria cultural de cada país y por la distinta función social que se le asigna a la figura del testigo, función que depende esencialmente del posicionamiento adoptado frente a los acontecimientos más traumáticos del propio pasado nacional.
\end{abstract}

Palabras clave: autobiografía, testimonio, literatura del Holocausto, literatura del testimonio latinoamericano, memoria cultural, Rigoberta Menchú, Enric Marco, Binjamin Wilkomirski

\begin{abstract}
:
This essay examines the critical reactions to the scandals associated with the testimonies of Rigoberta Menchú, Binjamin Wilkomirski and Enric Marco in order to undermine the different comprehension and reception of Holocaust testimonial literature and Latin American 'literatura del testimonio'. The critical responses to Rigoberta Menchú's autobiographical dishonesties as representative of the suffering of Guatemala's indigenous people and to Binjamin Wilkomirski's and Enric Marco's false testimonies as Holocaust survivors show that the comprehension of the testimonial genre depends in great part of the understanding of the limits between fictional and non-fictional genres, understanding which is strongly determinated by the different national memory cultures. The aim of this article is to critically challenge the role played by these different cultural memories in the reception of testimonial literature.
\end{abstract}

Keywords: autobiography, testimony, Holocaust literature, Latin American 'literatura del testimonio', cultural memory, Rigoberta Menchú, Enric Marco, Binjamin Wilkomirski

${ }^{1}$ Esta investigación ha sido llevada a cabo en el marco del Proyecto de investigación Topografías del recuerdo. Espacio y memoria en la narrativa alemana actual (FFI2015-68550-P) financiado por el Ministerio de Ciencia e Innovación y el Fondo Europeo de Desarrollo Regional (FEDER). 
Debido al extraordinario prestigio del que gozan hoy en día los testimonios de memorias de traumas sociales se ha hablado de nuestra era como de una "era del testigo" (Wieviorka). Esta sensibilidad frente a la cultura testimonial se desarrolló sobre todo a partir del Holocausto, que ha llegado a ser percibido como paradigmático en este sentido. 'Auschwitz' se ha convertido en un símbolo, en la cifra misma del mal. Ello ha dado lugar a un proceso de universalización que a veces induce a olvidar que todo testimonio está rodeado de una trama de interpretaciones que son las que determinan su impacto social, impacto que varía de unos países a otros dependiendo de la memoria cultural vigente. Se hace necesario, por tanto, estudiar el testimonio también como práctica social, cuyo significado depende no ya solo del testigo y de lo que relata, sino también del destinatario individual o colectivo que lo acoge.

Entender la literatura del testimonio como praxis social permite explicar las llamativas diferencias que cabe observar en el manejo de los criterios éticos y estéticos mediante los cuales se determina su valor. En el presente ensayo se analizarán algunas diferencias entre el posicionamiento adoptado por parte de la crítica a ambos lados del Atlántico, en países como España, Alemania, Suiza, Guatemala y otros países de América Latina, así como en EEUU, frente al testimonio. Ello se llevará a cabo a través del análisis de los escándalos por los que se vieron rodeados los testimonios de la activista guatemalteca Rigoberta Menchú, que obtuvo el Premio Nobel de la paz en 1992; de Enric Marco, que fue presidente de la Sociedad Amical de Mauthausen y otros campos y de todas las víctimas del nazismo de España; y del suizo Bruno Dössekker, conocido como Binjamin Wilkomirski, famoso por una autobiografía en la que describía sus presuntas experiencias en los campos de exterminio nazis. Las reacciones críticas suscitadas por dichos testimonios ilustran el distinto papel atribuido en diversas culturas de la memoria a la categoría de la autenticidad. En este contexto se revelan asimismo las diferencias existentes entre la crítica literaria surgida en torno a la Shoah y la que se ha desarrollado en relación con la literatura del testimonio latinoamericano. Tales diferencias se derivan en último término de la distinta función que cada cultura atribuye al testimonio en tanto que instrumento de denuncia de injusticias perpetradas en contextos históricos traumáticos.

\section{El caso Wilkomirski}

El escritor suizo Binjamin Wilkomirski alcanzó un gran prestigio literario a raíz de la publicación de su autobiografía Bruchstücke. Aus einer Kindheit 1939-1948 (1995), en donde narraba sus experiencias infantiles en los campos de concentración nazis (Wilkomirski). El texto, traducido tan solo dos años más tarde al castellano bajo el título de Fragmentos. De una infancia en tiempos de guerra, obtuvo numerosos premios literarios como el "National Jewish Book Award", concedido en Nueva York, el "Jewish Quaterly Literary Prize", obtenido en Londres, o el "Prix Mémoire de la Shoa" en Paris. El escándalo estalló dos años después de su publicación, cuando el escritor Daniel Ganzfried, hijo de supervivientes del Holocausto, demostró que Binjamin Wilkomirski se llamaba en realidad Bruno Dössekker, había nacido en Suiza, y nunca había estado en un campo de concentración a no ser como turista. El nombre de Binjamin Wilkomirski 
lo había adoptado ya de adulto a raíz del encuentro con un superviviente del Holocausto que creyó reconocer en él a un familiar. Para el historiador Stefan Mächler, Bruno Dössekker, alias Wilkomirski, no actuó de mala fe, sino bajo la influencia de un tratamiento psicoanalítico en el transcurso del cual descontextualizó los recuerdos infantiles previos a su adopción por parte del matrimonio Dössekker (Mächler). La susceptibilidad e incluso agresividad con la que Wilkomirski reaccionó frente a las preguntas que le fueron planteadas por Daniel Ganzfried convencieron a este de todo lo contrario; en su opinión, el autor no era víctima de falsos recuerdos, sino que mintió de forma consciente y deliberada. El complejo proceso de investigación acometido por Ganzfried para desenmascarar la impostura de Wilkomirski aparece documentado en su libro ...alias Wilkomirski. Die Holocaust-Travestie. Enthüllung und Dokumentation eines literarischen Skandals — ,....alias Wilkomirski. La parodia del Holocausto. Revelación y documentación de un escándalo literario"-, en donde describe las presiones que hubo de soportar durante dicho proceso de investigación, en el transcurso del cual fue acusado de actuar movido por la envidia. En su libro aparecen recogidas, asimismo, las reflexiones formuladas por personalidades como Imré Kertéz, Ruth Klüger ("Kitsch") o Claude Lanzmann una vez que se consideró probada la impostura gracias a la localización por parte de Ganzfried de la partida de nacimiento y los documentos de adopción de Dössekker. Aun así transcurrieron meses hasta que la editorial Suhrkamp tomara finalmente la decisión de retirar el libro del mercado, cosa que sucedió unos días antes de la emisión de un documental en la cadena de televisión suiza 3Sat y ante la inminente aparición de un artículo de Daniel Ganzfried en el semanario suizo Die Weltwoche titulado "Deutscher Verlag hält mit Hilfe von Schweizer Agentur an Holocaust-Lüge fest" (Ganzfried 151-152) — "Editorial alemana y agencia literaria suiza siguen avalando falsificación sobre el Holocausto"-.

Lo interesante del caso es que una vez que estalló el escándalo no solo se produjo una condena moral del autor, sino también una radical descalificación de su obra en términos literarios. A partir de ese momento el carácter altamente fragmentario de Bruchstücke, interpretado hasta este momento como síntoma de una memoria trabajosamente recuperada, pasó a ser entendido como parte integrante de una falsa retórica de la autenticidad. Lo mismo sucedió con la nitidez casi fotográfica de sus imágenes, que fueron reinterpretadas como reveladoras de la dependencia del autor de los documentos fílmicos y fotográficos en los que se apoyó a fin de suplir lo no vivido. Nadie invocó el argumento de que toda reconstrucción autobiográfica entraña un cierto grado de narrativización, y por tanto de falsedad, sino que se habló directamente de falsificación y de mentira. De nada le valieron a Wilkomirski sus aseveraciones de que todo cuanto había relatado tenía una base documental, pues se consideró que en vista del uso fraudulento que había hecho de las marcas de autenticidad esto ya no era relevante.

Las alabanzas que inicialmente contribuyeron al éxito mediático de Wilkomirski se convirtieron en una fuente de desprestigio para las personas e instituciones involucradas. En su descargo, estas señalaron que habían leído el texto como un testimonio, esto es, como un acto comunicativo encaminado a poner en conocimiento de la comunidad una injusticia padecida por el propio autor. Ello los habría inducido a dejar de lado las consideraciones de tipo estético o relacionadas con la verificabilidad de lo narrado para concentrarse en el relato de la experiencia. Dicho argumento fue ampliamente aceptado, también por parte de Elsbeth Pulver que no se había ocupado anteriormente del 
caso, pero que ahora señalaba que también a ella le hubiera resultado indecente y hasta inhumano desconfiar de un autor que se sometía a un proceso rememorativo tan traumático (Pulver 158). Elie Wiesel, escritor y superviviente de los campos de concentración, galardonado con el Premio Nobel de la Paz en 1986, decía haber pasado por una experiencia similar en relación con la supuesta autobiografía de Jerzy Kosinski Elpájaro pintado (1965), pues cuando Kosinski le comentó que se trataba de un texto autobiográfico, Wiesel rompió la recensión que ya tenía redactada y escribió otra nueva, mucho más elogiosa (Mächler 230), solo para enterarse unos años más tarde, en 1982, de que se trataba de un falso testimonio. En este contexto, no deja de resultar significativa la predilección que sentía Wilkomirski por este libro en particular, con el que su obra presenta, según Mächler, marcadas coincidencias (Mächler 230).

Especialmente sensible a la función apelativa de los textos testimoniales se muestra la crítica en países como Alemania, Israel o EEUU, en donde se ha gestado una cultura de la memoria fuertemente orientada a mantener vivo el vínculo con el pasado, potenciando la identificación con las víctimas. Los testimonios de los supervivientes son valorados en este tipo de comunidades rememorativas como un medio a través del cual establecer un lazo entre presente y pasado, entre las víctimas y la sociedad actual deseosa de ofrecerles una reparación, aunque tardía y puramente simbólica. De ahí la emotividad casi automática con la que se responde a la literatura testimonial del Holocausto. En cuanto se descubre, sin embargo, que el testimoniante ha abusado de la confianza que los lectores depositan en la referencialidad y veracidad de este tipo de textos, la especial empatía con la que son acogidos se torna en indignación.

Dentro del campo de la crítica literaria, esta cultura rememorativa se traduce en un tratamiento sumamente diferenciado de la literatura testimonial del Holocausto, a la que se aplican criterios de valoración distintos a los manejados en relación con las autobiografías comunes y corrientes, a las que se permite un cierto grado de libertad en relación con las fronteras existentes entre lo recordado y lo reinterpretado. No así en relación con la literatura testimonial, puesto que se entiende que los supervivientes del Holocausto no solo hablan por sí mismos, sino también en nombre de todos aquellos que no pudieron contar sus sufrimientos. El uso del "nosotros" por parte de tantos testimonialistas indica que también ellos se sienten dolorosamente conscientes de la responsabilidad que asumen en tanto que portavoces de un destino colectivo. Claude Lanzmann comenta en este sentido que desde un primer momento le irritó el carácter tan marcadamente egocéntrico del testimonio de Wilmomirski, pues al leer tenía la impresión de que ese "yo", "yo", "yo" nada tenía que ver con el "nosotros" utilizado habitualmente por parte de los supervivientes del Holocausto (Lanzmann 204).

Mientras que las autobiografías comunes y corrientes, no ligadas al Holocausto, son interpretadas ante todo como reflejo de una psicología individual y enjuiciadas principalmente en función de su calidad estética, a la literatura testimonial del Holocausto se la sitúa en los países germanoparlantes mucho más cerca del discurso histórico y documental, subrayando su compromiso con la verdad histórica. Las categorías estéticas más enfatizadas en relación con este tipo de literatura son las de la autenticidad (relativa a la vinculación del texto con un referente verificable) y la veracidad (referida al papel asumido por el narrador en tanto que testigo de los hechos relatados y garante de su verdad). Consecuentemente, cualquier apartamiento de la verdad y toda confusión consciente de las fronteras que separan lo ficcional de lo no ficcional es sancionada como una traición a la memoria de las víctimas y una vulneración del pacto 
autobiográfico y testimonial. Así lo ponen de manifiesto las reacciones críticas de los autores recogidos en la recopilación llevada a cabo por Daniel Ganzfried así como los análisis llevados a cabo por críticos como Sigrid Weigel, Willi Huntemann, Ruth Klüger ("Kitsch") o Aleida Assmann. En su libro Der lange Schatten der Vergangenheit. Erinnerungskultur und Geschichtspolitik _ „La larga sombra del pasado. Cultura de la memoria y política de la historia"-, Assmann argumenta que el género testimonial adoptado por Wilkomirski no solo le exige al autor respetar la verdad fáctica, relativa a los hechos, sino también la verdad autobiográfica, relativa a la categoría de la autenticidad. Apoyándose en una cita de Sigrid Weigel, que parte de la misma base, Assmann constata que en relación con la literatura testimonial no cabe hablar de un "testimonio ficticio", sino únicamente de un "testimonio simulado":

El género del testimonio impone una obligación moral al autor en tanto que "testigo moral" en relación con la veracidad de lo fáctico (¿qué es lo que exactamente he vivido?) y también con relación con la veracidad autobiográfica (ise trata realmente de vivencias mías?). Por esto no puede haber, como señala Sigrid Weigel, un testimonio "ficticio", sino tan solo un testimonio "simulado". (Assmann 163; traducción propia)

La especificidad de esta recepción crítica y sus implicaciones para el caso Wilkomirski ha sido muy bien descrita por Ruth Klüger, una reconocida germanista que goza además de un extraordinario prestigio en tanto que autora de una autobiografía sobre su internamiento en el campo de concentración de Theresienstadt (Klüger, Weiter leben). Para ella no cabe duda de que la autobiografía de Wilkomirski pierde todo su valor en vista de la falsificación identitaria perpetrada. Semejante impostura no puede ser paliada, en su opinión, a través de un re-etiquetado del texto como ficción, pues, implica una violación de la frontera que determina la realidad ontológica del texto. Desde su punto de vista, el escándalo suscitado por la autobiografía de Binjamin Wilkomirski demuestra que las fronteras genéricas entre los géneros ficcionales y no ficcionales tienen una base ontológica fundamental:

El motivo por el cual muchos lectores que se sintieron impresionados por Fragmentos dudan ahora de su juicio crítico es que, de forma completamente justificada, leemos de otra manera un libro que interpretamos como historia que otro que nos es presentado como ficción. Nos las tenemos que ver con un texto que ha cambiado, porque ha pasado de un género a otro. Ello nos ofrece un buen ejemplo de cómo varía el valor estético del texto a raíz de este cambio. (Klüger, Weiter leben 227; traducción propia)

Willi Huntemann expresa esta misma convicción en su artículo "Zwischen Dokument und Fiktion. Zur Erzählpoetik von Holocaust-Texten" - "Entre documento y ficción. Sobre la poética narrativa de la literatura del Holocausto"- publicado en la revista Arcadia. Internationale Zeitschrift für Literaturwissenschaft, en donde remarca la importancia de la categoría de la autenticidad como piedra de toque del reconocimiento concedido a los supervivientes del Holocausto en tanto que autores de testimonios:

Lo que tiene en común la literatura del Holocausto con la autobiografía es su carácter literario y la importancia concedida a la autenticidad, pero se diferencia en cuanto a su contenido en la medida en que no está centrada en un destino individual, sino colectivo. Ello acerca este tipo de textos al testimonio, radicalizando la exigencia de autenticidad 
hasta convertirla en la prohibición de ficcionalizar sus materiales. (Huntemann 23; traducción propia)

\section{E1 caso Enric Marco}

La impostura de Enric Marco se originó en 1976, en un momento en que a raíz de la muerte del dictador Francisco Franco muchas personas en España estaban reacomodando su relato autobiográfico a las nuevas circunstancias políticas y sociales. El falso testimonio de Enric Marco apareció recogido ya en la primera recopilación que se publicó en 1978 de los testimonios de los supervivientes españoles de los campos de concentración nazis en el libro de Eduardo Pons Prades y Mariano Costante Campo, Los cerdos del comandante (1978), y más adelante en la recopilación de David Bassa y Jordi Ribó Memòria de l'infern. Els supervivents catalans dels camps nazis (2002). La habilidad de Enric Marco a la hora de sacarle partido a esta identidad impostada se puso de manifiesto cuando fue elegido en 1977 Secretario General de la Federación catalana de la CNT y un año más tarde Secretario General de la CNT a nivel nacional, siendo expulsado de la misma en 1980. Su oportunismo quedó nuevamente demostrado cuando en el año 2000 inició su aproximación a las asociaciones españolas de las víctimas de los campos de concentración nazis, justamente en el momento en que se estaba iniciando en España el así llamado boom de la memoria. Meses más tarde se produjo su elección como presidente de la sociedad Amical de Mauthausen y otros campos, momento a partir del cual se convirtió en la cabeza visible de la organización, divulgando su falso testimonio a través de cientos de charlas y conferencias en escuelas, institutos, universidades y otros foros culturales. En 2005 hasta llegó a hablar en el Congreso de los Diputados en nombre de los casi nueve mil republicanos españoles deportados a los campos de concentración y exterminio del Tercer Reich.

El descubrimiento de su impostura se produjo en el año 2005 gracias al historiador Benito Bermejo, especializado en la investigación de las víctimas españolas de los campos. Hacía años que este había detectado contradicciones en el relato de Enric Marco y tenía noticias de lo reacio que se mostraba el presidente de la Amical a compartir sus recuerdos con otros supervivientes. Por otra parte, miembros de la CNT le habían comentado que el nombre de Marco no figuraba en las listas de afiliados durante el Franquismo, circunstancia que este justificaba aludiendo al carácter clandestino de sus actividades. Las sospechas que todo ello levantaba no se vieron confirmadas hasta que Benito Bermejo logró localizar en los archivos del Ministerio de Asuntos Exteriores un documento acreditativo de la incorporación voluntaria de Enric Marco a un contingente de trabajadores enviados a Alemania en 1941. Confrontado con dicha evidencia, Marco reconoció que al final de la guerra no cruzó la frontera con Francia para unirse a la resistencia francesa ni nunca estuvo en un campo de concentración ni formó parte de la resistencia antifranquista como siempre había afirmado. Insistía, no obstante, en que fue detenido por la Gestapo cuando trabajaba en unos astilleros de Kiel e internado en una cárcel común. A su entender, ello había entrañado un sufrimiento similar al de los supervivientes del Holocausto: 
Soy un embustero, sí, pero no un farsante, ni un falsario. Lo mío fue una simple distorsión de mi propia historia. Me convertí en la voz y el brazo de los deportados porque yo también sufrí cárcel en Alemania. Que me digan qué diferencia hay entre la cárcel y el campo de concentración. No solo fui esclavo de los nazis, también resistente. (Reportaje sobre Enric Marco: "Soy un embustero, pero no un falsario", El País (27 junio 2011))

La opinión pública se mostró indignada ante semejante impostura y los argumentos esgrimidos en artículos de opinión y las editoriales de los principales diarios fueron muy similares a los que aparecieron publicados en los medios suizos y alemanes a raíz del caso Wilkomirski. También en España se consideró que al presentarse falsamente como superviviente del Holocausto y miembro de la resistencia antifranquista, Enric Marco había profanado la memoria de las víctimas, tanto más cuanto que se había apropiado de su relato por motivos manifiestamente egoístas: "El inmenso respeto que cualquier bien nacido siente ante un superviviente de los campos de concentración nazis, ante uno de los republicanos españoles que allí murieron," escribía Joan Maria Tomás en La Vanguardia, "es intransferible". Y Gregorio Morán señalaba en el mismo diario que "Hay cosas con las que no se puede jugar, aquellas en las que cualquier frivolidad es crimen. Los campos de concentración nazis son una de ellas". De forma similar, en el editorial de El País del 27 de junio de 2005 se planteaba la pregunta de “¿Cómo se puede hollar con la mentira el territorio sagrado de la memoria europea donde reposan el sufrimiento y la desolación suprema, la degradación mecánica, industrial, del individuo, el ejercicio de la máxima ignominia y barbarie humana?"

Entre tantas reacciones indignadas hubo, sin embargo, algunas que, aun coincidiendo con las restantes en su rechazo moral del personaje, remarcaban el talento narrativo de Enric Marco. Una semana después de que estallara el escándalo aparecía publicado un artículo de Mario Vargas Llosa en El País en el que, al propio tiempo que manifestaba su repulsa moral ante la impostura de Enric Marco, le reconocía un extraordinario talento fabulador:

Sin embargo, a la par que mi repugnancia moral y política por el personaje, confieso mi admiración de novelista por su prodigiosa destreza fabuladora y su poder de persuasión, a la altura de los más grandes fantaseadores de la historia de la literatura. Éstos fraguaron y escribieron la historia del Quijote, de Moby Dick, de Los hermanos Karamazov. Enric Marco vivió e hizo vivir a cientos de miles de personas la terrible ficción que se inventó. (Vargas Llosa)

El novelista Juan José Millás declaraba en un programa radiofónico emitido por la Cadena Ser el 21 de noviembre de 2005 que "a través de la mentira [Enric Marco] ha contado aquello mejor que muchos que lo vivieron", opinión compartida por Javier Cercas que convirtió a Enric Marco en el protagonista de una de sus "docu-ficciones" titulada El impostor (2014), en donde reflexiona sobre la ficción como una forma de imaginación que se alimenta de las experiencias realmente vividas. Las largas y frecuentes entrevistas mantenidas con Enric Marco favorecieron seguramente la adopción de una posición un tanto ambivalente por parte de Cercas, que describe en su libro el feroz interrogatorio al que sometió a Enric Marco a fin de inducirle a confesar sus mentiras, pero al propio tiempo lo disculpa aludiendo a las miserables condiciones de vida que le llevaron a buscar refugio en una ficción compensadora. En cualquier caso 
Cercas coincide con Vargas Llosa a la hora de remarcar el extraordinario talento narrativo de Enric Marco, aunque al propio tiempo señala que el suyo era un relato particularmente kitsch, dado que escondía la verdad en lugar de revelarla como hacen los grandes narradores (Cercas 185).

Lo que parecen insinuar estos autores es que el testimonio de Enric Marco puede conservar su valor si es concebido como una ficción. Con ello dan carta de naturaleza al re-etiquetado que los críticos germanoparlantes descartaban tan categóricamente, y es que a su entender el caso de Enric Marco saca a relucir el carácter borroso de los límites entre los géneros documentales y ficcionales, recordándonos que el memorialista transita, igual que el novelista, por un espacio hecho de ausencias y de lagunas, motivo por el cual tiene que echar mano de la imaginación para dar cuerpo a sus recuerdos y urdir la trama de su relato. Esta relativización de las diferencias epistemológicas y ontológicas en las que se basa la frontera establecida entre los géneros ficticios y documentales contrasta fuertemente con la interpretación que se hizo en Suiza o Alemania del caso Wilkomirski en tanto que ejemplificación que validaba la existencia de dicha frontera. La cuestión que a mi juicio no cabe pasar por alto al posicionarse frente a cualquier desdibujamiento crítico de las fronteras entre una autobiografía común y corriente y la literatura testimonial es que semejante relativización de la diferencia entre la literatura del testimonio y otras manifestaciones literarias debilita la denuncia que este tipo de literatura hace de una determinada violación de los derechos humanos, porque la efectividad de su denuncia depende en última instancia de su valor documental. La relativización del papel del autor-narrador como testigo reduce la credibilidad de su testimonio en tanto que documento de una injusticia.

\section{El caso Rigoberta Menchú}

Coincidiendo con el quinto centenario de la llegada de Colón a América y con la declaración de 1993 como Año Internacional de los Pueblos Indios, en 1992 se concedió el Premio Nobel de la Paz a la activista guatemalteca Rigoberta Menchú en reconocimiento a su lucha por la justicia social y por el respeto a los derechos de los indígenas en Guatemala. Su fama provenía en gran parte del libro testimonial Me llamo Rigoberta Menchú y así me nació la conciencia (1985), surgido de una entrevista realizada en 1982 en París con la antropóloga de origen venezolano Elizabeth Burgos-Debrais. Dicho testimonio debe ser considerado, por tanto, como un "discurso testimonial mediato" (Sklodowska 109), producto de la colaboración establecida entre una testimoniante de veintidós años, que no estaba hablando en su lengua materna, el quiché, sino en español, y una académica que contaba con la formación y los contactos necesarios para que el libro apareciera publicado en la prestigiosa editorial Gallimard. La forma discursiva adoptada borra las huellas de la intervención de Burgos-Debrais, que figura como autora del libro, de tal forma que la voz que se oye es, según se nos asegura en el prólogo, la de la testimoniante. En la pormenorizada descripción que se ofrece en el prólogo del tratamiento al que fueron sometidos las materiales recopilados durante la semana de intensa convivencia en que tuvieron lugar las entrevistas, la autora insiste en que su intervención estuvo orientada a preservar la autenticidad del testimonio, limitándose a 
organizar los materiales recogidos en cintas magnetofónicas, agrupándolos temáticamente. ${ }^{2}$ Un dato fundamental para la valoración de la intencionalidad a la que obedece dicho testimonio por parte de la joven activista es que esta había sido enviada a París como representante del Comité de Unidad Campesina (CUC), integrado por aquel entonces en el Ejército Guerrillero de los pobres (EGP), a fin de dar a conocer al mundo el genocidio que se estaba perpetrando en Guatemala contra la población maya y mestiza. Gracias a la proyección nacional e internacional obtenida a raíz de la publicación de su testimonio, Rigoberta Menchú pudo configurarse en los años siguientes como una figura políticamente significativa en Guatemala, usando el prestigio obtenido en apoyo del proceso democrático de su país, todo lo cual la convirtió en un verdadero símbolo para América Latina.

Su prestigio se vio, sin embargo, cuestionado por la publicación de la investigación llevada a cabo por parte del antropólogo estadounidense David Stoll quien durante diez años se dedicó a reunir documentación relativa a los hechos relatados en el testimonio de Menchú, pretendiendo demostrar a través de 123 entrevistas con personas de su entorno que esta se había atribuido experiencias ajenas y había ocultado o falseado datos autobiográficos significativos (Stoll, Two Armies; Stoll, Rigoberta Menchû). Cierto es que tales acusaciones nunca hubieran alcanzado la difusión internacional que llegaron a tener de no ser por un artículo publicado en la primera página del New York Times el domingo 15 de diciembre de 1998, en donde Larry Rohter se hacía eco de las tesis de Stoll. En respuesta a las acusaciones vertidas contra ella, Menchú reconoció que efectivamente se había atribuido algunas vivencias ajenas, aunque al propio tiempo remarcaba que su intención nunca fue la de ofrecer un testimonio autobiográfico, sino la de narrar una experiencia colectiva, algo que ya había subrayado en su testimonio: "... no soy la única", remarcaba al comienzo del mismo, "pues ha vivido mucha gente y [lo que voy a contar] es la vida de todos." (Burgos 21)

Lo primero que se preguntaron los comentaristas latinoamericanos al reaccionar frente al artículo del New York Times fue por qué entre todas las noticias posibles sobre Guatemala se destacaban las investigaciones de un antropólogo prácticamente desconocido, empeñado en desacreditar el testimonio de una mujer que simbolizaba el reconocimiento internacional del genocidio perpetrado contra la población indígena de Guatemala. Desde su punto de vista, tanto el artículo de Rohter como la investigación de Stoll obedecían a una motivación ideológica orientada a empañar no ya solo la credibilidad de Rigoberta Menchú, sino la del movimiento de resistencia indígena, debilitándolo políticamente en un momento especialmente sensible en el que se estaban dirimiendo en Guatemala las pasadas responsabilidades del gobierno dictatorial y su ejército. Para articulistas como la escritora y catedrática guatemalteca Carolina Escobar Sarti (127), la escritora y periodista Margarita Carrera, también de Guatemala (139), o el escritor uruguayo Eduardo Galeano (99), así como muchos otros recogidos en el libro editado por Arturo Arias bajo el título The Rigoberta Menchú Controversy, no cabía duda de que este ataque mediático estaba enfocado a desviar la atención desde el terrorismo de estado hacia la responsabilidad de la guerrilla. Lo que se estaba tratando de hacer, en palabras de Eduardo Galeano, era "sentar a las víctimas en el banquillo de los acusados" (102).

${ }^{2}$ El complejo proceso de edición del texto también es comentado de forma muy interesante por Marina Martínez Andrade y por Gustavo V. García (207 y ss.). 
Pero no solo en Latinoamérica se procesaron las tesis de Rohter y Stoll como una injerencia de los EEUU en el proceso democratizador guatemalteco; también en EEUU fueron numerosos los académicos procedentes de disciplinas como la antropología, los estudios culturales y literarios que salieron en defensa de Rigoberta Menchú. Muchos habían incorporado su testimonio a sus programas lectivos, motivo por el cual se sintieron a su vez cuestionados por las críticas que ahora se dirigían contra ella. Todo ello hizo que la controversia muy pronto derivara hacia un debate entre los defensores del así llamado "canon occidental" y aquellos otros sectores que propugnaban la incorporación al canon de textos capaces de reflejar la otredad y la diferencia cultural, racial, de género y /o clase: "At one level, then, what is at stake in the United States is neither Menchú nor Guatemala, but academic authority" observaba Mary Louise Pratt (38). El propio Stoll salió al paso de las acusaciones vertidas contra él asegurando que no comenzó su investigación con la intención de desacreditar a Rigoberta Menchú, pero que, una vez descubiertas sus tergiversaciones, consideró que no podían ser pasadas por alto, puesto que infringían uno de los principios fundamentales de la literatura testimonial, que es el de dar fe de algo vivido personalmente, visto con los propios ojos: "What matters is that Menchú was not the eyewitness that she claimes to be" sentenciaba (Stoll, Rigoberta Menchú 120). Para Larry Rohter la raíz del problema estribaba en la pretensión de Rigoberta Menchú de recoger el sufrimiento de todo un pueblo: "By presenting herself as a everywoman, she has tried to be all things, to all people in a way no individual can be" (Rohter 65).

A estas primeras reacciones se fueron sumando estudios académicos como los de Duncan Earle o Daphne Patai, que llegaban a la conclusión de que, a fin de crear la ficción de un frente indígena sin fisuras, Menchú había ocultado las divisiones internas entre los indígenas que apoyaban a la guerrilla y los que la acusaban de atraer la represión del ejército sobre ellos. Su deseo de aumentar su propia representatividad en tanto que miembro del colectivo maya la habría inducido a ajustar su identidad a las expectativas asociadas a la literatura del testimonio latinoamericano en tanto que reflejo de una conciencia marginada, periférica, subalterna, exagerando su enraizamiento dentro de la cultura maya así como su papel en tanto que representante de una alteridad cultural. Esto la habría llevado a ocultar la formación recibida en un internado de monjas belga, presentándose como una analfabeta, minimizando sus conocimientos del castellano y omitiendo sus labores como catequista. Este tipo de omisiones estaban orientadas a disimular el proceso de 'ladinización' y aculturación, o transculturación, que tuvo que experimentar a fin de estar en condiciones de dar a conocer su testimonio. Por otra parte, en su relato Rigoberta Menchú se atribuye experiencias que son comunes al colectivo maya, pero que ella no ha vivido. Así, por ejemplo, cuando describe las durísimas condiciones de vida que tuvo que soportar cuando comenzó a trabajar a los ocho años junto con su madre y sus hermanos en una plantación de café, a pesar de que ella nunca trabajó en una finca (Burgos 55), o cuando relata cómo durante este periodo presenció la muerte de uno de sus hermanos por inanición. Especialmente impactante es la escena en la que describe cómo su hermano Petrocinio y otros guerrilleros fueron quemados públicamente ante sus propios ojos: "Le habían rasurado sus partes. No tenía la punta de uno de sus pechos y el otro lo tenía cortado. Mostraba mordidas de dientes en diferentes partes del cuerpo. Estaba toda mordida la compañera. No tenía orejas. Todos no llevaban parte de la lengua o tenían partida la lengua 
en partes. Para mí no era posible concentrarme, de ver que pasaba eso." (203) Su hermano y su madre efectivamente fueron secuestrados, torturados y asesinados por el ejército, pero parece que no ocurrió en su presencia ni sucedió tal y como ella lo describe. En respuesta a las acusaciones vertidas por David Stoll, la propia Menchú argumentó que silenció determinados episodios de su vida a fin de proteger la identidad de personas con las que convivió.

Todo ello parece indicar que Menchú efectivamente antepuso en muchos momentos el mensaje ideológico a la verdad de los hechos. Sus defensores tienden a restar importancia a estas distorsiones de la verdad, argumentando que lo que se dirime en el debate suscitado en torno a su testimonio es sobre todo la cuestión de quién cuenta con la autoridad necesaria para narrar (García 12, 205; Peris 199-205; Beverley 81). Así, John Beverley se muestra convencido de que lo que Stoll no le perdona a Menchú es el hecho de contar con una agenda propia en lugar de limitarse al papel de "informante nativa". Y sin embargo el propio Stoll también tiene, según Beverley, una agenda oculta, pues, lejos de limitarse a verificar "hechos ciertos", como afirma, hace todo lo posible por rebatir la tesis central de Menchú encaminada a demostrar que el conflicto armado surgió a consecuencia de la brutal represión a la que se veía sometida la población maya. Frente a esto, Stoll trata de demostrar que la guerrilla siempre fue parte del problema, puesto que forzó a muchas poblaciones a colaborar en su lucha contra el ejército, lo cual dio lugar a que los pobladores quedaran atrapados entre dos frentes.

Apoyándose en la tradición crítica surgida en torno a la literatura del testimonio en Latinoamérica, muy influenciada a su vez por la antropología y la historia oral, los defensores de Menchú argumentan que las distorsiones autobiográficas detectadas en su testimonio resultan de su pretensión de prestar voz a los sin voz a pesar de tener ya superada dicha condición subalterna. Esta es una contradicción que a su modo de ver está presente en buena parte de la literatura del testimonio, puesto que para representar la subalternidad hay que contar con capacidades discursivas que en realidad no son propias de dicho colectivo (García 12). Por esto, entienden que el sujeto indígena que finalmente aparece representado en la mayoría de los testimonios es casi siempre hasta cierto punto una construcción artificial. De ahí la necesidad que ven de relativizar la importancia de la categoría de la autenticidad en relación con estas manifestaciones testimoniales. En lugar de hacer depender sus valoraciones críticas de la autenticidad autobiográfica, estos investigadores ponen el acento en la función pragmática del testimonio como herramienta de emancipación política. Aplicado al caso de Rigoberta Menchú, ello les lleva a argumentar que lo más destacable de su testimonio es el papel que desempeña en tanto que discurso de lucha capaz de ofrecer una imagen narrativizada de una experiencia colectiva.

Esta comprensión de la literatura testimonial como reflejo de un colectivo se ve reforzada por la circunstancia de que la cultura maya apenas si ha dado lugar a textos autobiográficos, dado que la memoria tiene en ella una dimensión ante todo colectiva. Tal y como señalan Marc Zimmermann, Luis Aceituno, Jorge Skinner-Klee o George Lovell y Christopher Lutz, dentro de esta tradición rememorativa apenas si se diferencia entre experiencias propias y ajenas, pues los relatos heredados de los padres o de otros miembros de la comunidad son procesados como si formaran parte de la propia experiencia personal. "Lo que Stoll realmente no entiende", observa Arturo Taracena, que en su día organizó y asistió a parte de la entrevista entre Rigoberta Menchú y Eli- 
sabeth Burgos, colaborando posteriormente con la edición del libro, "es que un indígena a la hora de contar su historia se apoya tanto en el contexto individual como en el colectivo, interconectándolos" (Taracena cit. en Aceituno 91). Entender la literatura del testimonio como expresión de una experiencia comunitaria lleva a estos investigadores a restar importancia a las tergiversaciones autobiográficas de Menchú y a argumentar que lo relevante no es saber si su hermano efectivamente fue quemado vivo por el ejército en su presencia, como relata Menchú, o si fue muerto de un disparo después de ser secuestrado por el ejército, como pretende Stoll, sino que se trató de un asesinato político en medio de una atmósfera de terror como la que evoca Menchú en su testimonio:

Does it matter whether the Guatemalan army shot Menchu's brother or torched him alive? [...] Does it matter that one source of information says one thing and another something slightly different? Is not the most pertinent piece of information the incontestable fact that murder took place for political reasons in an atmosphere of terror that all parties not only agree upon [...]. (Lovell y Lutz 177)

Recordemos que la propia Rigoberta Menchú también insiste desde las primeras páginas de su testimonio en la dimensión colectiva de la experiencia narrada, remarcando su intención de hablar como "portavoz de su gente":

Me llamo Rigoberta Menchú. Tengo veintitrés años. Quisiera dar este testimonio vivo que no he aprendido en ningún libro y que tampoco he aprendido sola ya que todo esto lo he aprendido con mi pueblo y es algo que yo quisiera enfocar. [...] Quiero hacer un enfoque [en] que no soy la única, pues ha vivido mucha gente y es la vida de todos. La vida de todos los guatemaltecos pobres y trataré de dar un poco mi historia. Mi situación personal engloba toda la realidad de un pueblo. (Burgos 21)

Así y con todo, es importante observar que en esta cita tan significativa Menchú invoca categorías consideradas incompatibles, pues según la comprensión tradicional de las fronteras entre los géneros ficcionales y autobiográficos, a la hora de narrar una experiencia se hace necesario elegir entre la opción autobiográfica (que permite contar la propia historia individual abarcando una experiencia limitada) y la opción de contar una historia colectiva (para lo cual se hace necesario amalgamar voces e historias diferentes, ya sea a través de la ficción o a través del recurso a materiales documentales). Desde el momento en que Rigoberta Menchú pretende hacer las dos cosas a la vez, su testimonio contraviene estas nociones genéricas, circunstancia que desde mi punto de vista resulta clave para entender el debate suscitado entre sus críticos. Y es que, si se analizan los argumentos esgrimidos por unos y otros, se comprueba que se apoyan en dos tradiciones críticas encontradas. Quienes desarrollan su comprensión del testimonio a partir de la literatura testimonial sobre el Holocausto tienden a concebir la literatura testimonial ante todo como manifestación de la memoria individual, remarcando la importancia de las categorías de veracidad y autenticidad autobiográficas, lo cual les lleva a mostrarse bastante más críticos con el testimonio de Menchú. Aquellos otros que se apoyan más en la tradición crítica derivada de la literatura del testimonio latinoamericano tienden a entender el testimonio ante todo como manifestación de una identidad colectiva con una clara vocación de denuncia, motivo por el cual relativizan hasta cierto punto la categoría de la autenticidad, restando importancia al hecho de que 
el testimonio de Menchú incorpore experiencias no protagonizadas por ella misma. Ambas tradiciones críticas tienden a situar la literatura del testimonio más cerca del discurso histórico que del literario, pero desarrollan otra comprensión del concepto de referencialidad. De hecho, si se compara el debate surgido en torno a Rigoberta Menchú con los casos de Binjamin Wilkomirski y Enric Marco, se observa que los sectores más críticos con Menchú tienden a juzgar su testimonio en base a los mismos criterios que fueron aplicados a los casos de Binjamin Wilkomirski y Enric Marco, enfatizando el vínculo establecido con un referente individual, mientras que para los defensores de Menchú el texto va referido a una identidad colectiva, lo cual les lleva a entender de otra manera las categorías de autenticidad y veracidad.

\section{Correspondencias entre los tres casos}

La cuestión que se plantea al comparar estos tres casos es la de si hay que juzgarlos en función de los mismos criterios o si es posible rechazar como fraudulentos los testimonios de Binjamin Wilkomirski y Enric Marco y no hacer lo propio con el de Rigoberta Menchú. En este sentido, considero importante resaltar el hecho de que hay una diferencia fundamental entre ellos, dado que en el texto de Rigoberta Menchú las desviaciones de la verdad autobiográfica tienen un carácter más puntual, mientras que los otros dos testimonios están basados en la asunción de una falsa identidad, motivo por el cual resultan completamente fraudulentos. Aun así resulta innegable que todo desvío de la verdad repercute negativamente en la credibilidad de un relato testimonial, algo que apenas si ha sido reconocido por parte de los defensores de Rigoberta Menchú, que prefieren arremeter contra las investigaciones de David Stoll antes que enfrentarse a las contradicciones presentes en el testimonio. De hecho, entre los defensores de la Premio Nobel, y en la media en la que me ha sido dado comprobarlo, únicamente Marc Zimmermann parece dispuesto a admitir que las investigaciones del antropólogo norteamericano marcaron un antes y un después en su lectura del testimonio de Menchú, puesto que sacaron a relucir una serie de contradicciones que no pueden ser pasadas por alto independientemente de la opinión que merezca el posicionamiento ideológico de Stoll. Marc Zimmermann acierta, en mi opinión, al insistir en su libro Literatura y testimonio en Centroamérica: proposiciones postinsurgentes en la necesidad de llevar a cabo una relectura crítica del testimonio de Menchú, una relectura capaz de poner en valor la aportación del mismo sin por ello cerrar los ojos ante el impacto que tienen sus desvíos de la verdad testimonial:

Muchos desearíamos que ella no hubiera distorsionado o aumentado mucho, desearíamos que su narrativa hubiera expresado más extensamente las dimensiones contradictorias de las políticas indígenas, etc. Quedamos desconcertados con respecto a los asuntos que son importantes para nosotros. Sin embargo, no podemos deshacernos del problema simplemente rechazando a Stoll automáticamente o expresando nuestra frustración por su investigación o su calculada presentación. [...] Tengo la esperanza de que todos nosotros podamos usar el testimonio de Rigoberta Menchú y su más reciente libro [...] más críticamente y lo exploraremos yendo más allá de los usos simplistas de tiempos anteriores. (Zimmerman 209) 
Lo que no tiene sentido es tratar de relativizar la diferencia fundamental que existe entre sufrir un dolor en carne propia o ser testigo del dolor ajeno. No es lo mismo haber trabajado desde los ocho años de sol a sol en una plantación de café o relatar las experiencias de quienes sí han sufrido semejante destino. Presenciar un acto de tortura - ver como queman vivo a un hermano- es una experiencia traumática completamente diferente a los traumas asociados a la incertidumbre que rodea la figura de los desaparecidos. El argumento de que para la cultura indígena no sea relevante la diferencia entre las experiencias vividas en carne propia y las escuchadas o heredadas a través de los relatos de otros no resulta convincente en relación con una literatura centrada en experiencias tan traumáticas. Tanto más cuanto que el fuerte impacto ejercido por el libro de Burgos-Debrais en sus lectores se debe en gran parte a la impresión de inmediatez que produce un relato que desde el prólogo se presenta como la transcripción de la voz de una indígena de veintidós años dando fe de las desgracias padecidas por ella y su familia. Una vez que se rompe el pacto autobiográfico y testimonial así establecido, cambia inevitablemente la percepción que los lectores tienen del mismo, pues a partir de ese momento surge la pregunta por la intencionalidad ideológica o propagandística a la que obedecen tales tergiversaciones, lo cual da lugar a una actitud mucho más crítica y menos empática por parte de los lectores.

Una vez analizadas las diferencias entre estos tres casos, se hace necesario preguntarse por el porqué de la fuerte resistencia demostrada sobre todo por parte de la crítica latinoamericana a aplicarle al testimonio de Menchú los criterios de valor manejados en relación con los casos de Binjamin Wilkomirski y Enric Marco. El factor más importante fue sin duda el hecho de que el testimonio de Rigoberta Menchú iba referido a una memoria aún en construcción, una memoria que estaba denunciando el genocidio que se estaba perpetrando en esos momentos en Guatemala, mientras que los textos de Enric Marco y Binjamin Wilkomirski volvían sobre crímenes mucho más alejados en el tiempo, que ya contaban con un reconocimiento indiscutible. Al denunciar el carácter fraudulento de los falsos testimonios de Enric Marco o Binjamin Wilkomirski, los críticos suizos, alemanes o españoles estaban saliendo en defensa de una memoria oficial firmemente asentada en sus respectivos países. Por este motivo apenas si hubo disenso entre ellos a la hora de censurar lo que fue percibido como un atentado contra un lugar de memoria firmemente anclado en la memoria cultural. El testimonio de Rigoberta Menchú iba referido, en cambio, a una memoria que aún era objeto de debate social y político, motivo por el cual hubo mucho más lugar para el disenso. Y por otra parte resulta fundamental no olvidar que los crímenes denunciados por ella tenían un carácter mucho más urgente: el testimonio de Menchú desvelaba ante el mundo una tragedia que estaba alcanzando su punto álgido en el momento mismo en que apareció publicado el texto, y es que el genocidio maya se produjo específicamente entre 1981 y 1983; al mismo tiempo que la entrevista entre Rigoberta Menchú y Elisabeth de Burgos que tuvo lugar en 1982. Dos años antes, en 1980, había muerto el padre de Rigoberta Menchú, quemado junto a otras treinta y ocho personas en la Embajada de España en Ciudad de Guatemala; su madre y su hermano Petrocinio habían sido secuestrados, torturados y asesinatos por fuerzas del gobierno entre 1979 y 1980, y unos años más tarde, en 1984, se produciría el asesinato de otro hermano suyo.

Este es el marco en el que se inserta el debate desencadenado por las investigaciones de David Stoll, un marco que hay que tener muy presente a la hora de comprender la resistencia demostrada por buena parte de la crítica a cuestionar la legitimidad del 
testimonio de Rigoberta Menchú. Entre sus defensores se percibe la influencia de la tradición crítica desarrollada a partir de la así llamada literatura del testimonio latinoamericano, que en su caso tiene más peso que la tradición surgida en el entorno de la Shoah. A esta percepción del testimonio como un instrumento de lucha se une la convicción de que el propio posicionamiento crítico puede contribuir a modificar el lugar ocupado por Rigoberta Menchú dentro de la memoria cultural, de modo que para la mayor parte de los críticos lo más importante no es el testimonio de Menchú, sino la propia Rigoberta Menchú y su función social en tanto que lugar de memoria capaz de simbolizar la solidaridad para con las poblaciones indígenas y mestizas en Latinoamérica. Los propios críticos reconocen abiertamente que para ellos poner en duda la credibilidad del testimonio de Rigoberta Menchú equivale a atacarla a ella, lo cual a su vez supone debilitar la causa que representa. Mientras que con respecto a los casos Wilkomirski y Marco sucede justamente al contrario, atacándolos a ellos se refuerza el lugar de memoria que sus falsos testimonios amenazaban con empañar.

\section{Conclusiones}

Por un lado, las reacciones críticas aquí estudiadas ponen de manifiesto el carácter normativo del propio concepto de género literario, así como las dificultades inherentes a todo intento de delimitación. En "la loi du genre" (1980) — "La ley del género"Jacques Derrida observa con la lucidez que le caracteriza que el concepto de género no solo implica la presencia de una norma y de un límite, sino que siempre alude también a algo que amenaza con confundirse con lo que se pretende delimitar. El límite trazado en defensa de la pureza del género pone de manifiesto la presencia de aquello que desde fuera amenaza con hibridizarlo. Las discusiones críticas aquí analizadas ofrecen un ejemplo casi paradigmático de esta dialéctica del límite, pues, como se ha visto, las disensiones entre los críticos provienen de la diferente concepción que tienen del límite que separa el género testimonial del género autobiográfico, y también del límite que establecen entre la literatura y la historia. En efecto, dependiendo del lugar en el que es situada la literatura del testimonio con respecto a la literatura, por un lado, y a la historia, por otro, varía la importancia concedida a las categorías de veracidad y autenticidad. En Centroeuropa, en donde la literatura testimonial es situada muy cerca de la historia, se enfatizan especialmente las categorías de autenticidad y veracidad que vinculan el texto a su referente, aunque hay diferencias entre países como España, en donde se pone más énfasis en el hecho de que también el relato testimonial tiene una componente literaria significativa, y en Alemania, en donde se enfatiza la diferencia ontológica entre los géneros de ficción y no ficción. Frente a ello, la tradición crítica surgida en relación con la literatura del testimonio latinoamericano subraya sobre todo la función pragmática del testimonio en tanto que literatura de resistencia, a resultas de lo cual su posicionamiento con respecto a la historia o la literatura resulta más variable. Lo que se ha tratado de mostrar aquí es que tales diferencias no obedecen a motivos arbitrarios, sino que responden a los diferentes modelos de memoria cultural establecidos en dichos países.

Es decir que las reacciones críticas aquí estudiadas no solo ponen de manifiesto el carácter normativo del propio concepto de género literario, sino que ante todo mues- 
tran el papel ejercido por la memoria cultural de cada país en relación con los posicionamientos crítico-literarios frente a la literatura del testimonio. Como se ha visto, en el caso de Alemania y Suiza el establecimiento de fronteras tan rígidas entre los textos testimoniales sobre el Holocausto y otros textos literarios se ve propiciado por el proceso de sacralización experimentado por la Shoah, sacralización que tiene el efecto de hacer más empática la lectura de los textos producidos por los supervivientes de los campos, pero que también contribuye a acentuar la indignación frente a todo abuso del especial respeto con el que son acogidos los testimonios en tanto que relatos autobiográficos absolutamente auténticos y veraces. Quiere esto decir que la conceptualización de la literatura de la Shoah como un 'caso aparte', que no goza de las mismas libertades concedidas a una autobiografía común y corriente, se debe en último término al extraordinario valor concedido a los testimonios de los supervivientes.

En España el tratamiento crítico de la literatura testimonial del Holocausto parece verse influido por la recepción dispensada a la literatura sobre la guerra civil y el franquismo. La marcada obsesión demostrada por buena parte de esta literatura por propiciar una reconciliación de las memorias divididas explica el frecuente recurso a la ficcionalización de la memoria, dado que dentro del terreno de la ficción resulta más fácil realizar los ajustes requeridos a fin de establecer un precario equilibrio entre vencedores y vencidos (Cifre Wibrow). Ello ha contribuido, a mi juicio, a propiciar la flexibilización de las fronteras entre la ficción y la no ficción en relación con los relatos sobre las experiencias vividas durante la guerra civil y el franquismo, acostumbrando a la crítica a todo tipo de hibridaciones, e induciéndola a conceder menos importancia que en otros países como Alemania o Suiza al hecho de que tales hibridaciones restan fuerza a la denuncia que actúa como eje central de la literatura testimonial.

La recepción crítica de la literatura del testimonio latinoamericano tiende por ende a destacar ante todo el papel desempeñado por la literatura testimonial en tanto que elemento de anclaje del movimiento de resistencia indígena. Este es el principal reclamo con el que la literatura del testimonio latinoamericano atrae a sus lectores, invitándoles a solidarizarse a través de ella con un colectivo oprimido. El destino individual narrado aparece en ella como la encarnación de un destino colectivo. Al definir la literatura testimonial en base a la denuncia que hace de una injusticia, la crítica en realidad no hace más que hacerse eco de estas pautas de recepción. Por otra parte, la actualidad y la urgencia de los conflictos aludidos contribuyen a reforzar la importancia de su mensaje ideológico. Así lo ponen de manifiesto las airadas reacciones con las que los críticos latinoamericanos salieron mayoritariamente en defensa de Rigoberta Menchú. Para ellos no se trataba tan solo de defender a la activista, sino ante todo de proteger lo que ella simbolizaba, aunque ello entrañara la relativización de una serie de categorías éticas y estéticas como la veracidad o la autenticidad que en otros contextos sin duda hubieran destacado.

En último término los casos aquí analizados no solo ilustran las diferencias existentes entre las dos tradiciones críticas formadas a partir de la literatura del testimonio latinoamericano, por un lado, y la literatura testimonial del Holocausto, ya sea esta alemana, suiza o española, por otro, sino que además enfatizan el papel desempeñado por la cultura de la memoria de cada país. Lo que se ha podido observar aquí es que a la hora de regular la visibilidad, el significado y el impacto social de la literatura testimonial, la crítica se ve profundamente influída por la función social que la cultura de la memoria dominante en cada país atribuye a la figura del testigo, función que depende 
esencialmente de la disposición con la que cada sociedad se enfrenta a los acontecimientos más traumáticos de su pasado.

\section{Bibliografía}

Aceituno, Luis. "Arturo Taracena breaks his silence. Interview by Luis Aceituno." The Rigoberta Menchú Controversy. Ed. Arturo Arias. Minneapolis: University of Minnesota Press, 2001. 82-94.

Arias, Arturo. The Rigoberta Menchú Controversy. Minneapolis: University of Minnesota Press, 2001.

Assmann, Aleida. Der lange Schatten der Vergangenheit. Erinnerungskultur und Geschichtspolitik. München: C.H. Beck, 2011.

Bermejo, Benito y Sandra Checa. "La construcción de una impostura. Un falso testigo de la deportación de republicanos españoles a los campos nazis." Migraciones y Exilios 5 (2005): 63-80.

Beverley, John. Testimonio. On the Politics of Truth. Minneapolis: University of Minnesota Press, 2004.

Burgos, Elizabeth. Me llamo Rigoberta Menchú y asi me nació la conciencia. Barcelona: Seix Barral, 2007.

Carrera, Margarita. "Against Gerardi and Against Rigoberta. Attacks Are Continually Made to Make them Loose Some of their Luster." The Rigoberta Menchú Controversy. Ed. Arturo Arias. Minneapolis: University of Minnesota Press, 2001. 107-108.

Cercas, Javier. El impostor. Barcelona: Random House, 2014.

Cifre Wibrow, Patricia. "Las relaciones presente-pasado en el panorama crítico-literario español y alemán”. La memoria novela II. Ficcionalización, documentalismo y lugares de la memoria en la narrativa memorialista española. Ed. Juan Carlos Cruz Suárez y Diana González Martín. New York, Berlin, Bruxelles et al.: Peter Lang, 2013. 63-82.

Derrida, Jacques. “La loi du genre.” Glyph 7 (1980): 176-201.

Earle, Duncan. "Menchú Tales and Maya social Landscapes. The Silencing of Words and Worlds." The Rigoberta Menchú Controversy. Ed. Arturo Arias. Minneapolis: University of Minnesota Press, 2001. 288-308.

Escobar Sarti, Carolina. "A Hamburger in Rigoberta's Black Beans." The Rigoberta Menchú Controversy. Ed. Arturo Arias. Minneapolis: University of Minnesota Press, 2001. 127-129.

Felman, Shoshana y Laub, Dori. Testimony. Crises of Witnessing in Literature. Psychoanalysis, and History. New York/London: Routledge, 1992.

Forcinito, Ana. Los umbrales del testimonio. Entre las narraciones de los sobrevivientes y las señales de la postdictadura. Madrid/Frankfurt am Main: Iberoamericana/Vervuert, 2012. 
Galeando, Eduardo. "Let's Shoot Rigoberta." The Rigoberta Menchú Controversy. Ed. Arturo Arias. Minneapolis: University of Minnesota Press, 2001. 99-102.

Ganzfried, Daniel. ... alias Wilkomirski. Die Holocaust-Travestie. Enthüllung und Dokumentation eines literarischen Skandals. Berlin: Jüdische Verlagsanstalt, 2002.

García, Gustavo V. La literatura testimonial latinoamericana. (Re)presentación y (Auto)construcción del sujeto subalterno. Madrid: Editorial Pliegos, 2003.

Hefti, Sebastian. "Hat der Mensch, was es zum Gutsein braucht?" ...alias Wilkomirski. Die Holocaust-Travestie. Entbüllung und Dokumentation eines literarischen Skandals. Ed. Daniel Ganzfried. Berlin: Jüdische Verlagsanstalt, 2002. 7-15.

Huntemann, Willi. "Zwischen Dokument und Fiktion. Zur Erzählpoetik von Holocaust-Texten." Arcadia. Zeitschrift für Allgemeine und Vergleichende Literaturwissenschaft 36 (2001): 21-45.

Kertéz, Imre. "Wichtig ist die Öffentlichkeit." ...alias Wilkomirski. Die Holocaust-Travestie. Entbüllung und Dokumentation eines literarischen Skandals. Ed. Daniel Ganzfried. Berlin: Jüdische Verlagsanstalt, 2002. 207-218.

Klüger, Ruth. Weiter leben: Eine Jugend. München: Dtv, 1997.

Klüger, Ruth. "Kitsch ist immer plausibel. Was man aus den erfundenen Erinnerungen des Binjamin Wilkomirski lernen kann.” ... alias Wilkomirski. Die Holocaust-Travestie. Enthüllung und Dokumentation eines literarischen Skandals. Ed. Daniel Ganzfried. Berlin: Jüdische Verlagsanstalt, 2002. 225-228.

Klüger, Ruth. Gelesene Wirklichkeit. Fakten und Fiktionen in der Literatur. Göttingen: Wallstein Verlag, 2006.

Lanzmann, Claude. "Der organisierte Übergang zum Vergessen.” ...alias Wilkomirski. Die Holocaust-Travestie. Enthüllung und Dokumentation eines literarischen Skandals. Ed. Daniel Ganzfried. Berlin: Jüdische Verlagsanstalt, 2002. 197-206.

Lipstadt, Deborah. Denying the Holocaust. The Growing Assault on Truth and Memory. New York: Free Press, 1993.

Lovell, W. George y Christopher H. Lutz. "The Primacy of Larger Truths: Rigoberta Menchú and the Tradition of Native Testimony in Guatemala." The Rigoberta Menchú Controversy. Ed. Arturo Arias. Minneapolis: University of Minnesota Press, 2001. 171-197.

Mächler, Stefan. Der Fall Wilkomirski. Über die Wahrheit einer Biographie. Zürich: Pendo Verlag, 2000.

Marco Batlle, Enrique. “Testimonio de Enrique Marco Batlle.” Los cerdos del comandante. Ed. Eduardo Pons Prades y Mariano Constante. Barcelona: Argos Vergara, 1979. 87-90.

Marco, Enric. "Testimoni”. Memòria de l'infern. (Els supervivents catalans dels camps nazis). Ed. David Bassa y Jordi Ribó. Barcelona: Edicions 62, 2002, 307-324. 
Martínez Andrade, Marina. "Entre la oralidad y la escritura. El testimonio de Rigoberta Menchú." Literatura sin fronteras. Segundo congreso nacional de literatura. Ed. Ramón Alvarado, Laura Cázares, Alejandra Herrera y Marina Martínez. Medellín: Universidad Autónoma Metropolitana, 1999. 583-592.

Morán, Gregorio. “La naturaleza del impostor.” La Vanguardia (18 junio 2005).

Rahola, Pilar. "Enric Marco, el fraude." El País (14 mayo 2005).

Patai, Daphne. "Whose truth? Iconicity and Accuracy in the World of Testimonial Literatures." The Rigoberta Menchú Controversy. Ed. Arturo Arias. Minneapolis: University of Minnesota Press, 2001. 270-287.

Peris Blanes, Jaume. Historia del testimonio chileno: de las estrategias de denuncias a las politicas de la memoria. Valencia: Publicacions de la Universitat de València, 2008.

Pratt, Mary Louise. "Rigoberta Menchú and the 'Culture Wars'." The Rigoberta Menchú Controversy. Ed. Arturo Arias. Minneapolis: University of Minnesota Press, 2001. 29-57.

Pulver, Elsbeth. “'der wisse nicht, wovon er rede'. Gedankenmäander an den Rändern eines literarischen Skandals.” ... alias Wilkomirski. Die Holocaust-Travestie. Entbüllung und Dokumentation eines literarischen Skandals. Ed. Daniel Ganzfried. Berlin: Jüdische Verlagsanstalt, 2002. 155-165.

Rodríguez, Danilo. "The Primacy of Larger Truths. Rigoberta Menchú and the Tradition of Native Testimony in Guatemala." The Rigoberta Menchú Controversy. Ed. Arturo Arias. Minneapolis: University of Minnesota Press, 2001. 70.

Rohter, Larry. "About Rigobertas Lies.” The Rigoberta Menchú Controversy. Ed. Arturo Arias. Minneapolis: University of Minnesota Press, 2001. 70-72.

Roig, Montserrat. Els catalans als camps nazis. Barcelona: Edicions 62, 2001.

Skinner-Klee, Jorge: “About David Stoll's Book Rigoberta Menchu and the Story of All Poor Guatemalan". The Rigoberta Menchú Controversy. Ed. Arturo Arias. Minneapolis: University of Minnesota Press, 2001. 97-98.

Sklodowska, Elzbieta. Testimonio hispano-americano. Historia, teoría, poética. New York: Peter Lang 1992.

Stoll, David. Between Two Armies in the Ixil Towns of Guatemala. New York: Columbia University Press, 1993.

Stoll, David. Rigoberta Menchú and the Story of all Poor Guatemalas. Boulder: Westview Press, 1999.

Stoll, David. "The Battle of Rigoberta." The Rigoberta Menchú Controversy. Ed. Arturo Arias. Minneapolis: University of Minnesota Press, 2001. 392-410.

Tomás, Joan Maria. "El general Della Rovere y el señor Marco.” La Vanguardia 23 mayo 2005).

Vallina, Cecilia (Ed.). Crítica del testimonio. Ensayos sobre las relaciones entre memoria y relato. Rosario: Beatriz Viterbo Editora, 2009.

Vargas Llosa, Mario. "Piedra de toque: Espantoso y genial.” El País (15 mayo 2005). 
Washima, Eugenia y Ximena Carrasco. El testimonio como escritura subalterna. Análisis del Concurso Mujer: Imágenes y testimonios. Cuenca: Ediciones Universidad de Cuenca, 2005.

Weigel, Sigrid. "Zeugnis und Zeugenschaft, Klage und Anklage." Zeugnis und Zeugenschaft. Jahrbuch des Einsteinforums. Berlin: Akademie Verlag, 1999. 120-123.

Weintraub, Karl J. “Autobiografía y conciencia histórica.” Anthropos, Número extraordinario 29: La autobiografía y sus problemas teóricos. Estudios e investigación documental (1991): 18-33.

Wilkomirski, Binjamin. Bruchstücke. Aus einer Kindheit 1939-1948. Frankfurt am Main: Jüdischer Verlag bei Suhrkamp, 1995.

Wieviorka, Annette. L'Ère du témoin. Paris: Plon, 1998.

Zimmerman, Marc. Literatura y testimonio en Centroamérica: posiciones postinsurgentes. Houston: LACASA/University of Houston, 2006. 